\title{
Effects of Phosphonic Acid Monolayers on the Dehydration Mechanism of Aliphatic Alcohols on $\mathrm{TiO}_{2}$
}

\author{
Jordi Ballesteros-Soberanas ${ }^{\dagger}$, Lucas D. Ellis ${ }^{\dagger}$, J. Will Medlin ${ }^{\dagger *}$ \\ ${ }^{\dagger}$ Department of Chemical \& Biological Engineering, University of Colorado, Boulder, CO 80309
}

\begin{abstract}
The kinetics for surface-catalyzed alcohol dehydration reactions often depends on the structure of the alcohol. Studies of structure-activity relations across primary, secondary, and tertiary alcohols can provide fundamental information on the nature of active sites on the surface. Here, we investigated the dehydration of 1-butanol, 2-butanol and tert-butanol over $\mathrm{TiO}_{2}$ anatase catalysts modified with various phosphonic acid (PA) self-assembled monolayers (SAMs). As a response to the presence of PAs, the three $\mathrm{C} 4$ alcohol isomers showed different dehydration rates, with 1-butanol dehydration being enhanced to the greatest extent by PA modification. Furthermore, the fluorinated, more polar 4-fluorobenzyl phosphonic acid outperformed alkyl PAs across all alcohols. Steady-state kinetic measurements and temperature programmed desorption studies indicated that PA SAMs significantly lowered the dehydration activation barrier; the extent of reduction in the barrier was sensitive to both the substitution of the alcohol and the charge distribution on the PA in a way that was consistent with stabilization of a carbenium-like transition state. Overall, the effect of PA modifiers on alcohol dehydration rates was found to be determined from a balance between transition state stabilization and active site blocking effects, with the potential to tune activity and selectivity based on the structure and coverage of the SAM.
\end{abstract}

Dehydration, $\mathrm{TiO}_{2}$, Self-Assembled Monolayer, Phosphonic Acid, Alcohol, Metal Oxide

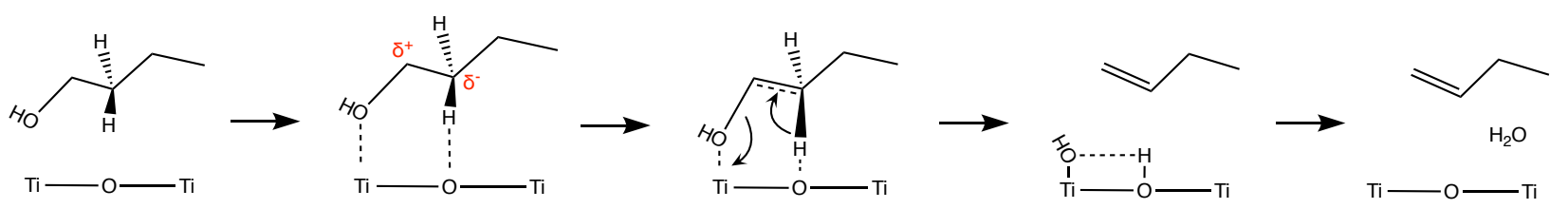

Scheme 1: Concerted dehydration mechanism for 1-

butanol.

\section{INTRODUCTION}

Interest in synthesis of olefins from alcohol dehydration over metal oxide catalysts has risen in the last decade because of its key role in the upgrading of biomass derived products $^{1-5}$. Due in part to the complexities of metal oxide surfaces, the mechanism for reactions of alcohols is not fully understood. Oxides such as $\mathrm{Al}_{2} \mathrm{O}_{3}$ and $\mathrm{TiO}_{2}$ are wellknown dehydrogenation and dehydration catalysts ${ }^{6,7}$. It is generally agreed that on oxides with Lewis acid sites, the metal acts as an electron acceptor during dehydration, thus bonding to a partially charged hydroxyl group, and lattice oxygen atoms bind to $\mathrm{H}$ atoms, as depicted in Scheme 1. Previous studies of alcohol dehydration on alumina ${ }^{8,9}$ and titania $^{10}$ agree that a sequential mechanism is unfavorable. Instead, a concerted elimination mechanism with a partially charged carbocation has been proposed (Scheme 1), implying that the degree of substitution of the alpha carbon plays a determinant role in the reaction outcome through charge stabilization ${ }^{11}$.
The use of organic ligands as selectivity modifiers has been reported for a number of reactions ${ }^{12-16}$, including alcohol dehydration on metal oxides. An advantage of the use of self-assembled monolayer (SAM) modifiers is that the ligands can be tuned to understand key aspects of the reaction mechanism. Ellis et al. studied the reactions of primary alcohols over $\mathrm{TiO}_{2}$ anatase and showed a large increase in the selectivity toward dehydration over dehydrogenation after SAM deposition ${ }^{17}$. Furthermore, the dehydration rate was found to be strongly correlated to the dipole moment of the organophosphonic acid layers. A recent publication explored the behavior of other metal oxides under the same conditions ${ }^{18}$. Intriguingly, only materials that fell in a certain range of metal - oxygen bond strength, including $\mathrm{TiO}_{2}$ anatase, were positively affected by the presence of phosphonate SAMs.

It has previously been proposed that the electrostatic field caused by the presence of SAMs stabilizes the transition state for alcohol dehydration. Specifically, density functional theory calculations indicated that the imposition 
of electric fields changed the lengths of the $\mathrm{C}_{\beta}-\mathrm{H}$ and $\mathrm{Ti}$ Oalcohol bonds to change the "lateness", and therefore energy, of the transition state ${ }^{17}$. The extent of transition state stabilization would be expected to be dependent on the structure of the alcohol. For example, it is known that through hyperconjugation tertiary alcohols can more easily stabilize the alpha carbon charge than primary alcohols, making the former much more reactive than the latter ${ }^{10,19}$. Therefore, the elongation of the $\mathrm{C}_{\beta}-\mathrm{H}$ bond, which places more charge on this same carbon and thus stabilizes the localized positive charge in the carbocation, should prove more beneficial to alcohols with a lower substitution degree. These factors we hypothesized to lead to a promoting effect of the SAM that differs for primary, secondary, and tertiary alcohols. The work described here examined this relationship between alcohol structure and extent of SAM promotion as a means to probe the mechanism for alcohol dehydration.

\section{EXPERIMENTAL METHODS}

\section{Catalyst Synthesis.}

Anatase phase $\mathrm{TiO}_{2}$ powder $(\geq 99 \%$ metal basis, $\sim 325$ mesh, Sigma Aldrich) was functionalized with: 4fluorobenzyl phosphonic acid (4-FBPA, $\geq 98.5 \%$, Sigma Aldrich), methyl phosphonic acid (MPA, $\geq 98 \%$, Sigma Aldrich) or octadecyl phosphonic acid (ODPA, $\geq 97 \%$, Alfa Aesar) by submerging the $\mathrm{TiO}_{2}$ powder into a $10 \mathrm{mM}$ solution of the phosphonic acid in tetrahydrofuran (THF) ( $\geq 99.9 \%$ anhydrous, Sigma Aldrich) and allowing to mix overnight. The solids were centrifuged and then annealed at $120^{\circ} \mathrm{C}$ for 6 hours. After cooling to room temperature, the powders were rinsed with tetrahydrofuran and centrifuged three times to remove any physisorbed phosphonic acids.

\section{Catalyst Characterization}

Brunauer-Emmet-Teller (BET) surface areas were determined for the metal oxides using a Micrometrics (Norcross, GA) Chemisorb 2720. The samples were pretreated for $1 \mathrm{~h}$ at $200^{\circ} \mathrm{C}$ in $30 \% \mathrm{~N}_{2} / 70 \% \mathrm{He}$. The reported surface areas were determined from the desorption peaks. Triplicate measurements were performed on each substrate. (Supporting Information, Table S1).

Diffuse reflectance infrared Fourier transform spectroscopy (DRIFTS) was performed using a Thermo Scientific Nicolet 6700FT-IR and confirmed the presence of the monolayers on the oxide. The experiments were performed at room temperature. Both $\mathrm{C}-\mathrm{H}$ and $\mathrm{C}-\mathrm{F}$ stretching regions were analyzed to capture the characteristic vibrational modes of all the monolayers used in this study. (Supporting Information, Figure S1).

\section{Reaction Studies}

1-Butanol (1-BuOH) (Fisher BioReagents), 2-butanol (2-BuOH) (Anhydrous $\geq 99.5 \%$, Sigma Aldrich), tertbutanol (t-BuOH) (Certified, Fisher Chemical), and water (HPLC Grade Submicron Filtered, Fisher Chemical) were used in these experiments. All reactions were performed in a continuous flow reactor, where the catalyst was placed in between glass wool inside a 0.5" diameter Pyrex tube. The catalyst powder was purged at room temperature with He for $15 \mathrm{~min}$ and heated to reaction temperature in the same inert gas., prior to introducing the alcohol in the system. Reaction rates were measured at $230 \stackrel{\circ}{ } \mathrm{C}$ for $\mathrm{t}-\mathrm{BuOH}$ and at $250^{\circ} \mathrm{C}$ for $1-\mathrm{BuOH}$ and $2-\mathrm{BuOH}$. Apparent activation energies were determined using different temperature ranges: $250-310^{\circ} \mathrm{C}$ for $1-\mathrm{BuOH}, 210-290^{\circ} \mathrm{C}$ for $2-$ $\mathrm{BuOH}$ and $150-230^{\circ} \mathrm{C}$ for $\mathrm{t}-\mathrm{BuOH}$, with measurements at intervals of $20^{\circ} \mathrm{C}$. Pressure was always kept at atmospheric levels. Helium was used as the carrier; it was bubbled through the liquid phase reactant inside a temperature-controlled bath. The temperature of the bath was kept at $10^{\circ} \mathrm{C}$ for $1-\mathrm{BuOH}$ and $2-\mathrm{BuOH}$, while it was kept at $25^{\circ} \mathrm{C}$ for $\mathrm{t}-\mathrm{BuOH}$, due to its higher melting point. These temperatures were held constant for all apparent activation energy experiments.

In order to change the alcohol concentrations to determine apparent reaction orders, the bath temperature was set at 5,10 and $15^{\circ} \mathrm{C}$ for $1-\mathrm{BuOH}$ and $2-\mathrm{BuOH} ; 25,30$ and $35{ }^{\circ} \mathrm{C}$ for $\mathrm{t}-\mathrm{BuOH}$. For determination of reaction orders with respect to water, the amount of co-flowed water covered a range of at least 1 to 3 times the stoichiometric amount produced by the dehydration reaction of each alcohol at steady state.

The flow rate was kept at $15 \mathrm{sccm}$, and all He flow passed through the bubbler except for the tertiary alcohol, which required a split flow of $2 \mathrm{sccm}$ through the bubbler and a 13 sccm makeup stream of pure helium to achieve a desired reactant concentration. The outlet of the reactor was connected to an Agilent 7280A GC for online analysis. The chromatograph was equipped with a $30 \mathrm{~m}$ x $0.250 \mathrm{~mm}$ Agilent DB-WAX capillary column and a flame ionizer detector. All experiments were run for $200 \mathrm{~min}$ to ensure a reliable steady state measurement.

All rates were measured keeping a differential $(<15 \%)$ conversion. Apparent reaction orders have been determined by fitting the data in a linear regression on a logarithmic plot.

\section{TPRS and TPD experiments}

Temperature programmed reaction spectroscopy (TPRS) was performed in a continuous flow reactor with a He carrier gas, similar to that used in the reaction studies. The outlet was continuously monitored by a Pffeiffer Vacuum Prisma quadrupole mass spectrometer, where mass fragments relevant to the alcohols, olefins, aldehydes, ketones, ethers and water were tracked. To ensure a strong enough signal, approximately $100 \mathrm{mg}$ of native material and $250-300$ mg of coated material were used for these experiments. After annealing under flowing He at $250^{\circ} \mathrm{C}$ for 2 hours, the samples were saturated with alcohols at $50^{\circ} \mathrm{C}$ and the reactant flow was stopped when the signal 
remained constant. The system was purged for $20 \mathrm{~min}$ again with helium to remove any physisorbed material. The $20^{\circ} \mathrm{C} / \mathrm{min}$ temperature ramp started at $50^{\circ} \mathrm{C}$ and continued to $550^{\circ} \mathrm{C}$.

All MS signals have been normalized according to a standard measured for a set flow rate of the alcohol from the same day, to remove any day-to-day fluctuations. Additionally, the olefin signal $(\mathrm{m} / \mathrm{z}=41)$ was also a fragment of the reactant. Two peaks appeared in the product signal and the position of the low-temperature peak always matched that of the unreacted alcohol desorption peak. Hence, the spectra were deconvoluted by subtracting a constant proportion of the reactant signal $(\mathrm{m} / \mathrm{z}=31,45$ and 59 for $1-\mathrm{BuOH}, 2-\mathrm{BuOH}$ and $\mathrm{t}-\mathrm{BuOH}$, respectively) from the olefin signal, effectively removing the secondary peak. The experiments were repeated twice and the observed peak positions remained constant, within $\pm 10^{\circ} \mathrm{C}$.

For water desorption experiments the surfaces were not pretreated. Instead, water was dosed on the fresh samples. For these experiments, $100 \mathrm{mg}$ of catalyst were loaded for both the native and SAM-coated materials. The same ramp, flowrate and dosing procedure used for the TPRS studies were used for water TPD experiments.

\section{RESULTS}

\section{Catalytic Performance}

A series of catalysts - unmodified $\mathrm{TiO}_{2}$ along with $\mathrm{TiO}_{2}$ modified by 4-FBPA, MPA, and ODPA-were evaluated in a flow reactor for reactions of the various $\mathrm{C} 4$ alcohols. Over native $\mathrm{TiO}_{2}$ anatase, the main pathway for $1-\mathrm{BuOH}$ was dehydrogenation, though dehydration and some minor condensation was also observed. 2- $\mathrm{BuOH}$ also underwent both dehydration and dehydrogenation, but with an increased selectivity for dehydration as compared to the primary alcohol. The tertiary alcohol t-BuOH only yielded dehydration products due to the inability to form an aldehyde group without undergoing $\mathrm{C}-\mathrm{C}$ cleavage.

Deposition of phosphonates led to major changes in

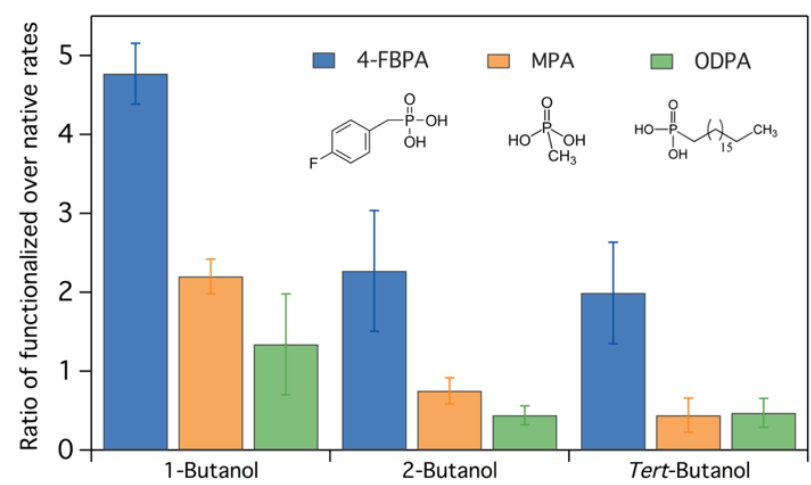

Figure 1: Ratio of dehydration rates for functionalized to native $\mathrm{TiO}_{2}$ for various alcohols. Reactions performed at $230^{\circ} \mathrm{C}$ for tert-butanol, $250^{\circ} \mathrm{C}$ for 1-,2-butanol.

reaction rates and selectivities. Those differences in performance are summarized in Figure 1. All the phosphonic acids promoted 1-BuOH dehydration, with the fluorinated ligand exhibiting the greatest enhancement. This result is consistent with previous reports ${ }^{17}$. For 2$\mathrm{BuOH}$ and $\mathrm{t}-\mathrm{BuOH}$, 4-FBPA still promoted the dehydration reaction, but to a smaller extent. For the substituted alcohols, ODPA and MPA no longer promoted
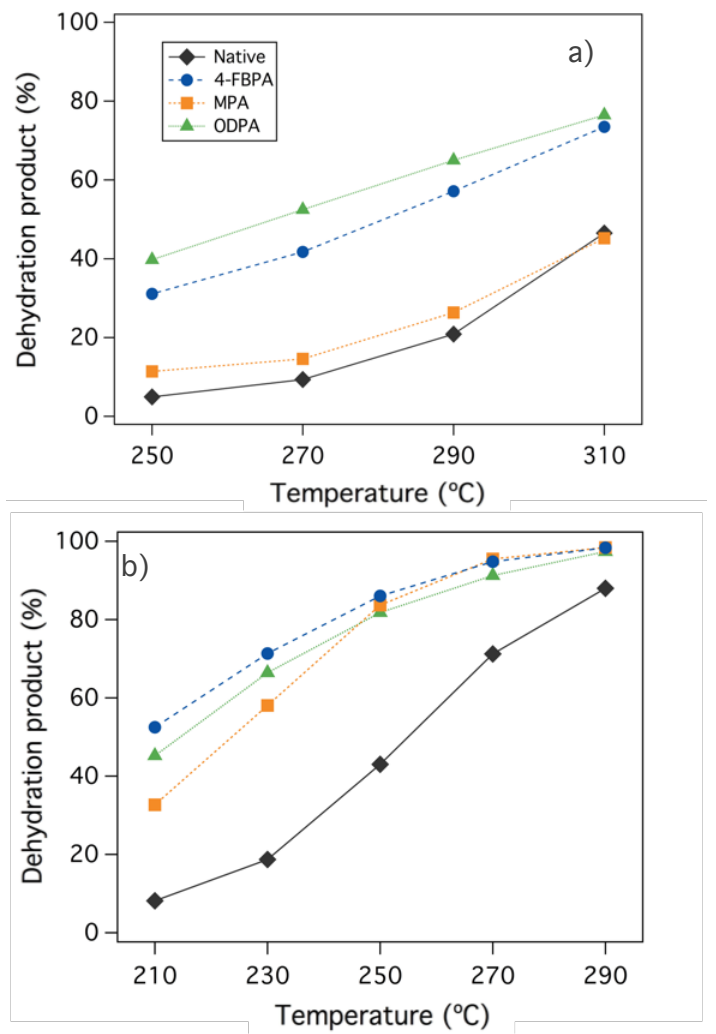

Figure 2: Dehydration product selectivity as a percentage of the total produced for a) 1-butanol and b) 2-butanol, mole basis.

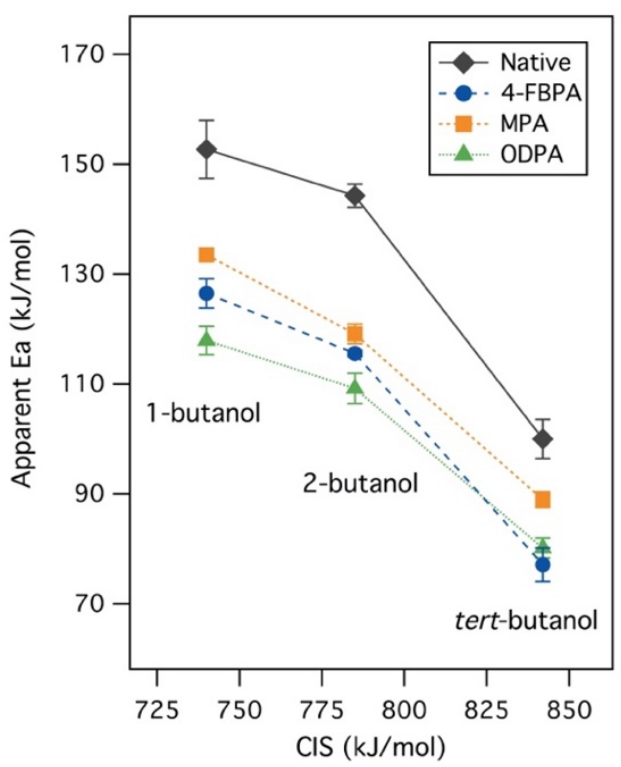

Figure 3: Apparent dehydration activation energies for 1butanol, 2-butanol and tert-butanol over native and functionalized $\mathrm{TiO}_{2}$, as a function of the carbenium ion stability (CIS). 
dehydration, but instead weakly suppressed it. Thus, it can be seen that the substitution of the alcohol led to a weakening of the ability of PAs to promote the reaction.

Interestingly, dehydrogenation rates went down for both the primary and secondary alcohols (Supporting Information, Figure S2), giving rise to the enhancement in the selectivity shown in Figure 2. Selectivity towards dehydration increased across all temperatures for the PAfunctionalized catalysts. Over all catalysts, there was a preference for dehydrogenation at lower temperatures for both $1-\mathrm{BuOH}$ and $2-\mathrm{BuOH}$, which is in agreement with previous observations of other short chain alcohols on $\mathrm{TiO}_{2}{ }^{7}$, and indicates a higher apparent activation barrier for dehydration.

In order to assess the effect of the monolayers on the reaction kinetics, apparent activation barriers were found for all combinations of reactants and catalysts (Figure 3 and Figure S3). Here, on the horizontal axis, each alcohol reactant is reported based on its carbenium ion stability (CIS), previously reported in the literature. ${ }^{11}$ This stability refers to the proton affinity of the alkenes involved in the reaction, as shown in Equation 1, where $\mathrm{E}$ values represent the energies for the subscripted species, $\mathrm{C}_{\mathrm{n}} \mathrm{H}_{2 \mathrm{n}}$ corresponds to the neutral alkene, and $\mathrm{C}_{\mathrm{n}} \mathrm{H}_{2 \mathrm{n}+1}{ }^{+}$corresponds to the corresponding carbenium ion. The CIS represents the stability of the cation that forms after the removal of the $\mathrm{OH}$ group, and has been shown to correlate linearly ${ }^{8}$ to the dehydration barriers.

$$
\text { CIS }=\left|E_{\mathrm{C}_{n} \mathrm{H}_{2 \mathrm{n}+1}}{ }^{+}-\mathrm{E}_{\mathrm{C}_{n} \mathrm{H}_{2 \mathrm{n}}}\right|
$$

PA-modified surfaces have lower barriers for all dehydration reactions. MPA had the lowest effect on the apparent barrier, while ODPA and 4-FBPA caused a greater activation energy reduction. These observed reductions decreased with alcohol substitution. For all catalysts, the activation energies decreased as the degree of alcohol substitution was increased, as expected ${ }^{11}$. Based on bond dissociation enthalpies in the gas phase reported in the literature, $\mathrm{C}_{\beta}-\mathrm{H}$ bonds weaken when the carbon is multiply substituted, while $\mathrm{C}-\mathrm{OH}$ bond enthalpies remain nearly constant ${ }^{8,20}$. Thus, the general trend in the barriers can be explained by making the proton transfer being involved in the rate-limiting step ${ }^{8}$.

We also measured apparent reaction orders in the reactant (Table 1). The order for the primary alcohol increased from negative-order to near zero-order in the presence of SAMs, consistent with previously reported measurements during 1-propanol dehydration ${ }^{17}$. 2-BuOH exhibited a positiveorder dependence on the reactant concentration, with values close to 0.48 , the partial reaction order for dehydration that Rekoske et al. observed at $548 \mathrm{~K}$ with 2propanol $^{7}$, with no great changes after functionalization. Orders for $\mathrm{t}-\mathrm{BuOH}$ were only positive in the presence of SAMs. On the unmodified catalyst, the reaction order was slightly negative, indicating a change in the surface caused by PAs. Thus, there was a general trend of PA SAMs increasing the alcohol reaction order, though the extent of this increase varied depending on the alcohol.

The reaction orders with respect to water were also measured, since water has been suggested to often play an important role as a surface species ${ }^{10}$. Over $\mathrm{TiO}_{2}$, alcohols have been shown to compete with water for active sites ${ }^{10}$, thus making the water desorption process important in controlling the rate. Accordingly, the presence of water resulted in a decrease of the dehydration rates, the magnitude of which was proportional to the degree of substitution of the alcohol. The presence of 4-FBPA dramatically reduced the negative impact of water in alcohol dehydration: reaction orders were found to be close to zero across reactants (Table 2).

Table 1: Apparent reaction orders for 1-butanol, 2-butanol and tert-butanol dehydration over functionalized and nonfunctionalized $\mathrm{TiO}_{2}$ anatase. Uncertainties represent the standard error calculated based on linear regression.

\begin{tabular}{lccc}
\hline & 1-Butanol & 2-Butanol & Tert-butanol \\
\hline Native & $-0.58 \pm 0.04$ & $0.37 \pm 0.04$ & $-0.20 \pm 0.03$ \\
4-FBPA & $-0.02 \pm 0.03$ & $0.67 \pm 0.06$ & $0.46 \pm 0.07$ \\
MPA & $-0.15 \pm 0.01$ & $0.51 \pm 0.05$ & $0.65 \pm 0.07$ \\
ODPA & $0.14 \pm 0.00$ & $0.64 \pm 0.05$ & $0.68 \pm 0.02$ \\
\hline
\end{tabular}

Table 2: Apparent reaction orders for water, co-fed with 1butanol, 2-butanol and tert-butanol over native $\mathrm{TiO}_{2}$ anatase. Uncertainties represent the standard error calculated based on linear regression.

\begin{tabular}{lccc}
\hline & Water $+1-\mathrm{BuOH}$ & Water $+2-\mathrm{BuOH}$ & Water $+\mathrm{t}-\mathrm{BuOH}$ \\
\hline Native & $0.09 \pm 0.01$ & $-0.25 \pm 0.01$ & $-0.51 \pm 0.02$ \\
4-FBPA & $0.06 \pm 0.01$ & $-0.08 \pm 0.01$ & $-0.09 \pm 0.01$ \\
\hline
\end{tabular}

Over both native and SAM-modified materials, the alcohols showed different behaviors in the recorded time on stream (TOS) data that led to the steady state (Supporting Information, Figure S4). The primary alcohol deactivated the catalyst, and the TOS data described an inverse exponential curve. The secondary and tertiary alcohol exhibited an apparent activation in the TOS data, which mostly followed a decaying exponential trend. The catalyst activation period was more pronounced for the tertiary alcohol.

\section{TPRS and TPD studies}

Temperature programmed reaction spectroscopy (TPRS) experiments were carried out on the various catalysts as a means to quantify sites and elementary reaction step barriers. We focused on temperatures below $400^{\circ} \mathrm{C}$ because PAs were found to decompose above $400^{\circ} \mathrm{C}$ on $\mathrm{TiO}_{2}{ }^{21}$.

The most relevant mass fragments for the native and coated catalysts are presented in Figure 4. Over native $\mathrm{TiO}_{2}$, desorption of unreacted 1-butanol and 2-butanol occurred 
at $\sim 150{ }^{\circ} \mathrm{C}$; tert-butanol (e) desorbed at roughly $120^{\circ} \mathrm{C}$. Phosphonic acids lowered the desorption temperature of these species by no more than $10^{\circ} \mathrm{C}$. A single peak was observed, likely representing a single population of weakly bound alcohols. Upon functionalization, the amount of reactant desorbing from the surface dropped to less than half due to site blocking and steric hinderance.

In absence of PAs, desorption of 1-butene, 2-butene and isobutene (b, d, f) occurred at approximately 345, 260 and $190{ }^{\circ} \mathrm{C}$, respectively. All three SAMs decreased these desorption temperatures. In particular, 4-FBPA reduced the desorption temperature by $30-40^{\circ} \mathrm{C}$ (Table 3). Alkyl SAMs had a milder impact, with reductions ranging between $5-30{ }^{\circ} \mathrm{C}$. Olefins bind much more weakly ${ }^{22}$ to the surface of metal oxides than alcohols, due to the lack of polar groups. Hence, these changes in the desorption temperature were attributed to a change in the dehydration activation energy. Calculated energies agree with those observed in Figure 3.
Table 3: Peak temperatures and activation energies of alcohol desorption and dehydration reactions, based on Redhead ${ }^{23}$ model assuming first order desorption and a standard pre-exponential

\begin{tabular}{|c|c|c|c|c|c|c|}
\hline & & Catalyst & $\mathrm{Tp}\left({ }^{\circ} \mathrm{C}\right)$ & $\begin{array}{c}\mathrm{Ea} \\
(\mathrm{kJ} / \mathrm{mol})\end{array}$ & $\begin{array}{c}\Delta \mathrm{Ea} \\
(\mathrm{kJ} / \mathrm{mol})\end{array}$ & Peak Area* \\
\hline \multirow{12}{*}{ 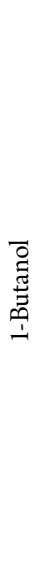 } & \multirow{4}{*}{ 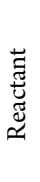 } & Native & $150.4 \pm 3.2$ & $118.2 \pm 0.9$ & - & 1.00 \\
\hline & & 4-FBPA & $143 \pm 1.4$ & $116.1 \pm 0.4$ & $2.1 \pm 1.4$ & $0.43 \pm 0.05$ \\
\hline & & MPA & $143.4 \pm 1.8$ & $116.2 \pm 0.5$ & $2.0 \pm 1.5$ & $0.31 \pm 0.05$ \\
\hline & & ODPA & $142 \pm 3.2$ & $115.8 \pm 0.9$ & $2.4 \pm 1.9$ & $0.30 \pm 0.05$ \\
\hline & & Native & $345.1 \pm 2.5$ & $174.4 \pm 0.7$ & - & 1.00 \\
\hline & & 4-FBPA & $319.6 \pm 5.6$ & $167.0 \pm 1.7$ & $7.4 \pm 2.4$ & $0.24 \pm 0.06$ \\
\hline & & MPA & $324.2 \pm 10.2$ & $168.3 \pm 3.0$ & $6.1 \pm 3.8$ & $0.16 \pm 0.01$ \\
\hline & & ODPA & $318.5 \pm 6.1$ & $166.7 \pm 1.8$ & $7.7 \pm 2.6$ & $0.15 \pm 0.05$ \\
\hline & \multirow{4}{*}{$\begin{array}{l}\frac{\pi}{2} \\
\frac{0}{0} \\
\frac{\pi}{2}\end{array}$} & Native & $355 \pm 9.4$ & $177.2 \pm 2.8$ & - & 1.00 \\
\hline & & 4-FBPA & $362.8 \pm 5.6$ & $179.5 \pm 1.7$ & $-2.3 \pm 1.7$ & $0.53 \pm 0.05$ \\
\hline & & MPA & $358.8 \pm 4.0$ & $178.4 \pm 1.2$ & $-1.1 \pm 1.2$ & $0.34 \pm 0.17$ \\
\hline & & ODPA & $370.8 \pm 6.0$ & $181.8 \pm 1.8$ & $-4.6 \pm 1.8$ & $0.46 \pm 0.09$ \\
\hline \multirow{12}{*}{ 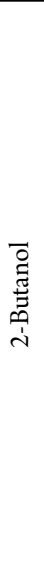 } & \multirow{4}{*}{ 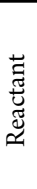 } & Native & $157.6 \pm 12.0$ & $120.2 \pm 3.5$ & - & 1.00 \\
\hline & & 4-FBPA & $143.1 \pm 5.9$ & $116.1 \pm 1.7$ & $4.1 \pm 5.3$ & $0.44 \pm 0.03$ \\
\hline & & MPA & $148.6 \pm 5.0$ & $117.6 \pm 1.5$ & $2.5 \pm 5.0$ & $0.27 \pm 0.16$ \\
\hline & & ODPA & $137.8 \pm 1.8$ & $114.6 \pm 0.5$ & $5.6 \pm 4.0$ & $0.51 \pm 0.22$ \\
\hline & \multirow{4}{*}{$\frac{\text { 责 }}{0}$} & Native & $263.6 \pm 3.6$ & $150.8 \pm 1.1$ & - & 1.00 \\
\hline & & 4-FBPA & $230.4 \pm 2.4$ & $141.2 \pm 0.7$ & $9.6 \pm 1.8$ & $0.14 \pm 0.04$ \\
\hline & & MPA & $250.3 \pm 3.8$ & $146.9 \pm 1.1$ & $3.9 \pm 2.2$ & $0.07 \pm 0.03$ \\
\hline & & ODPA & $249.8 \pm 4.3$ & $146.8 \pm 1.3$ & $4.0 \pm 2.3$ & $0.06 \pm 0.03$ \\
\hline & \multirow{4}{*}{ 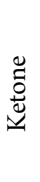 } & Native & $373.4 \pm 1.4$ & $182.6 \pm 0.4$ & - & 1.00 \\
\hline & & 4-FBPA & $365.2 \pm 2.3$ & $180.2 \pm 0.7$ & $2.4 \pm 1.1$ & $0.41 \pm 0.28$ \\
\hline & & MPA & $380.4 \pm 9.2$ & $184.6 \pm 2.7$ & $-2.0 \pm 3.2$ & $0.25 \pm 0.17$ \\
\hline & & ODPA & $368.1 \pm 3.1$ & $181.1 \pm 0.9$ & $1.6 \pm 1.3$ & $0.38 \pm 0.30$ \\
\hline \multirow{8}{*}{ 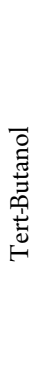 } & \multirow{4}{*}{ 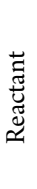 } & Native & $124.2 \pm 6.6$ & $110.6 \pm 1.9$ & - & 1.00 \\
\hline & & 4-FBPA & $122 \pm 5.2$ & $110.0 \pm 1.5$ & $0.6 \pm 3.5$ & $0.17 \pm 0.08$ \\
\hline & & MPA & $117.8 \pm 6.6$ & $108.8 \pm 1.9$ & $1.8 \pm 3.9$ & $0.35 \pm 0.05$ \\
\hline & & ODPA & $118 \pm 6.0$ & $108.9 \pm 1.8$ & $1.8 \pm 3.7$ & $0.18 \pm 0.03$ \\
\hline & \multirow{4}{*}{$\frac{\text { 常 }}{0}$} & Native & $187 \pm 3.8$ & $128.7 \pm 1.1$ & - & 1.00 \\
\hline & & 4-FBPA & $140.8 \pm 2.0$ & $115.4 \pm 0.6$ & $13.3 \pm 1.7$ & $0.31 \pm 0.04$ \\
\hline & & MPA & $180.6 \pm 7.4$ & $126.8 \pm 2.2$ & $1.9 \pm 3.3$ & $0.08 \pm 0.04$ \\
\hline & & ODPA & $159.1 \pm 2.1$ & $120.7 \pm 0.6$ & $8.0 \pm 1.7$ & $0.05 \pm 0.03$ \\
\hline
\end{tabular}

${ }^{*}$ Peak areas are normalized by the native signal.

factor of $10^{13} \mathrm{~s}^{-1}$.

A single peak was observed for the desorption of the olefins. Because olefin production is reaction-limited, this suggests that dehydration is catalyzed by a relatively homogeneous set of sites ${ }^{10,11,24}$. However, under the experimental conditions, deposition of SAMs severely reduced the amount of accessible sites for the dehydration reaction channel, as seen by the peak area reductions in Figure 4.

Dehydrogenation products were measured for 1-butanol and 2-butanol (Supporting Information, Figure S5). A site loss comparable to that of dehydration was observed, but 

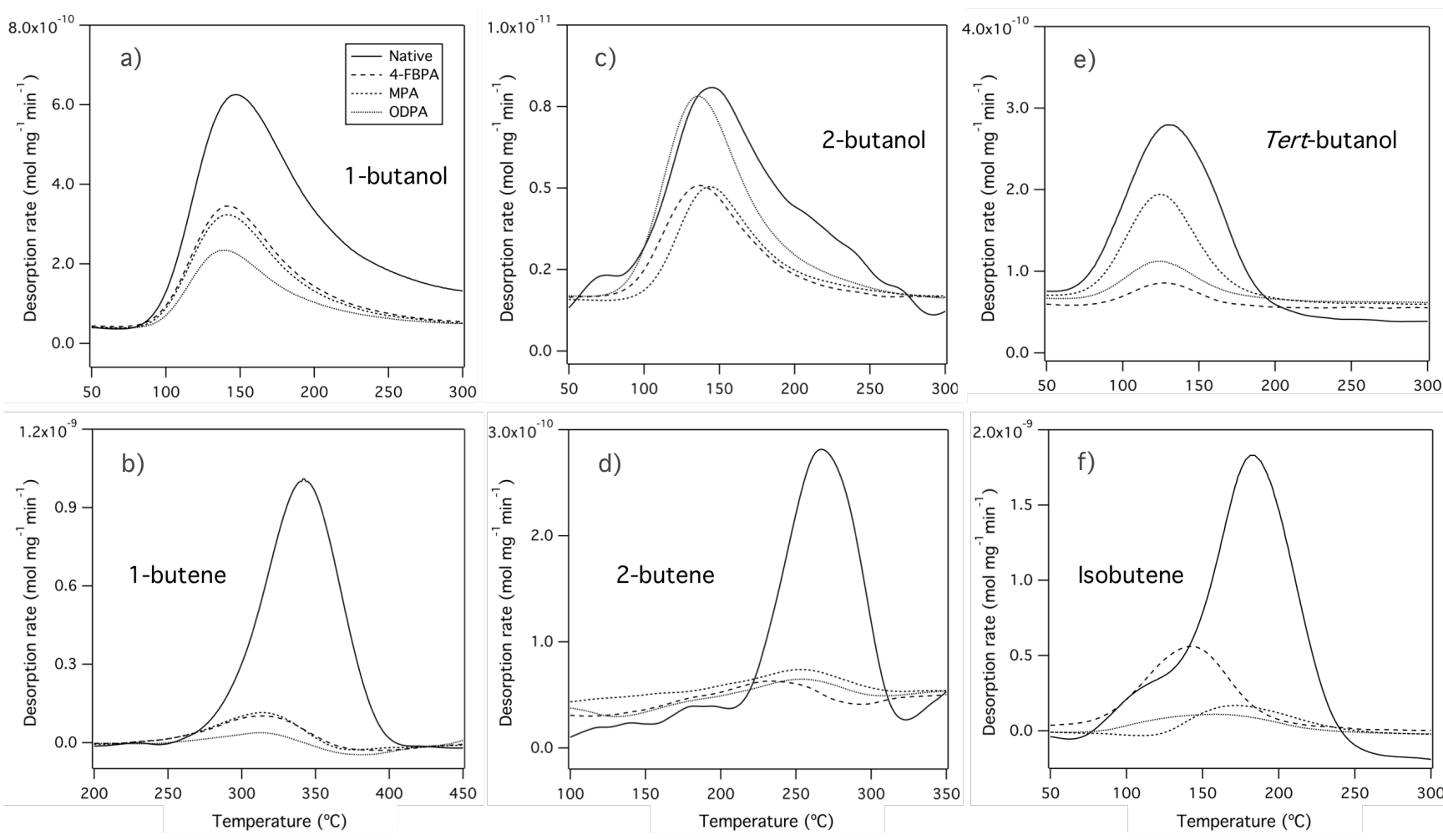

Figure 4: Temperature programmed desorption results for 1-butanol $(a, b), 2$-butanol $(c, d)$ and tert-butanol $(e, f)$. ( $a, m / z=31),(c$, $m / z=45)$ and $(e, m / z=59)$ correspond to the unreacted alcohols. (b), (d) and (f) correspond to the dehydration product ( $\mathrm{m} / z=41)$. Flowrate $=25 \mathrm{sccm} ; \beta=0.333 \mathrm{~s} / \mathrm{K} .{ }^{*} 2$-butene (Saytzeff olefin) is the main product of the reaction over TiO ${ }_{2}$ anatase $^{10}$.

no compensating barrier reduction resulting from SAM deposition was found. This is consistent with the uniformly decreased dehydrogenation rates measured in steady-state experiments. Numerical results can be found in Table 3.

Temperature programmed desorption (TPD) of water from the various surfaces revealed lower water coverages, along with a slight upward shift in desorption temperature for the modified catalysts (Supporting Information, Figure S6). However, desorption temperatures for water were found to be similar to those reported in previous studies ${ }^{7,24,25}$ of $\mathrm{TiO}_{2}$. This suggests that the PAs adsorbed in such a way that weaker water adsorption states were preferentially suppressed or new strong adsorption sites involving the PA group were created. Irreversible surface dehydration was observed at high temperatures on the native surface, a reported behavior for reducible metal oxides such as $\mathrm{TiO}_{2}{ }^{26}$. However, at the studied temperatures of up to $500^{\circ} \mathrm{C}$, no defects were created when the surface contained PAs, which could be indicating that the PAs increased the metal-oxygen bond strength through charge transfer effects $^{27}$.

\section{DISCUSSION}

We found that PAs have a different overall effect on the dehydration rates of each alcohol. After functionalization with 4-FBPA, dehydration rates of all alcohols increased, especially for the primary alcohol. MPA and ODPA improved dehydration rates for $1-\mathrm{BuOH}$, but had an overall negative effect in the rates of 2- $\mathrm{BuOH}$ and $\mathrm{t}-\mathrm{BuOH}$ (Figure 1). In the following discussion, we consider the roles of several factors in controlling the mechanism of alcohol dehydration: (i) the alcohol functional group position within the reactant, which dictates both the steric demands and the electronic properties of the transition state; (ii) the phosphonic acid head group, which can block $\mathrm{TiO}_{2}$ sites and potentially introduce new sites on the catalytic surface; and (iii) the tail of the self-assembled monolayer, which governs the surface coverages and the strength of the nearsurface electrostatic fields through its dipole moment.

\section{Influence of reactant structure on reaction barriers}

It is generally agreed that dehydration over metal oxides occurs through a concerted mechanism, where the proton transfer limits the process ${ }^{8,28}$, with carbenium ion stability of the putative transition state correlating with the activity of the reactant for the elimination reaction ${ }^{11}$. Based on this description of the transition state, more substituted alcohols have lower dehydration barriers (as observed in Figures 3 and 4).

As shown in Figure 3, PA SAMs reduced the dehydration barriers for all alcohols; the extent of barrier reduction was found to be inversely related to the alcohol substitution. Similar trends were observed in the TPRS experiments (Figure 4): dehydration product peak temperatures were generally found to decrease for all alcohols on PA-coated surfaces, but the decrease was largest for the primary alcohol 1-BuOH. Previous modeling studies have 


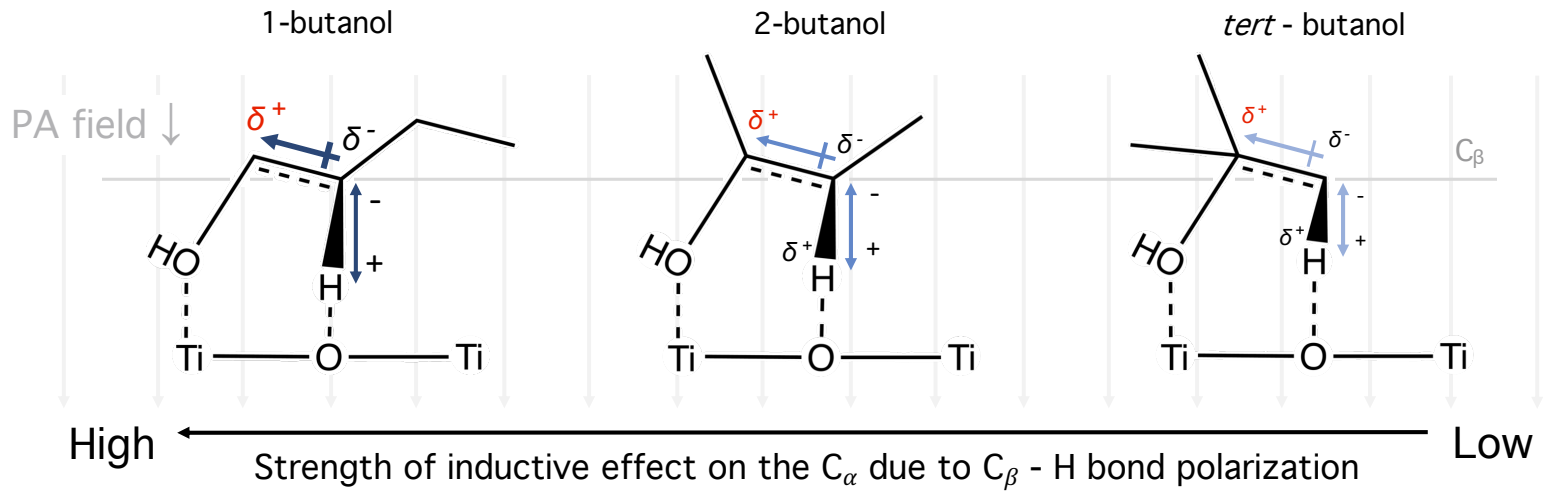

Scheme 2: Effect of the near-surface electrostatic fields induced by PA at the $\mathrm{TiO}_{2}$ surface on the $\mathrm{C}_{\beta}$ - $\mathrm{H}$ bond. Polarization of the bond creates a partial charge that stabilizes the carbocation.

indicated that PAs may decrease the barrier for primary alcohol dehydration in part via dipole interactions that stabilize the dehydration transition state. ${ }^{17}$ This dipole stabilization effect would be expected to diminish for more highly substituted alcohols, which stabilize the localized charges of their $\mathrm{C}$ atoms in the transition state through inductive effects ${ }^{29}$ (Scheme 2).

We note that, in contrast to alcohol dehydration, the activation energies for dehydrogenation obtained in the same experiments (Table 3) showed no dependence on the presence of PAs on the surface. This indicates that PAs have a negligible effect on the transition state of this undesired reaction, though they do lower the reaction rate significantly, likely through site blocking.

\section{Influence of PA modifiers on adsorption strength}

TPD studies of the various alcohols (Figure 4) showed a slight but consistent weakening of the alcohol-surface interaction energy caused by PA deposition, as indicated by a shift in desorption peaks to lower temperature (Table 3 ). There are also indications from the kinetic studies that PA deposition decreased the adsorption energy of alcohols and alcohol-derived intermediates. The increase in apparent reaction orders for 1-butanol dehydration (Table 1) suggests a lower fractional site occupation by butanolderived surface intermediates associated with a decrease in binding affinity. Orders for 1-butanol increased from -0.58 to close to zero-order after PA deposition (Table 1). This increase in reaction orders is usually linked to a decrease in the fractional coverage of strongly adsorbed reactantderived species on active sites. Also consistent with a general decrease in surface intermediate coverages is the fact that the condensation rates for 1-butanol were reduced by a factor of $\sim 4$ when MPA was deposited, with similar effects for the other two PAs. Ellis et al. observed the same effect with 1-propanol, and attributed it to the lack of the necessary adjacent sites caused by the interruption of the catalytic surface ${ }^{17}$.

In the absence of PA modifiers, the $\mathrm{t}-\mathrm{BuOH}$ reaction order was found to be only slightly negative, suggesting a decreased propensity for alcohol-derived intermediates to block reactant sites. Again, modification with PAs increased the reaction order, in this case to a significant positive order (Table 1). Previous work showed that alcohols can coordinatively adsorb in groups of 2 or 3 around an oxide active site on acid metal oxides, resulting in a reduction of the site activity ${ }^{30,31}$. Because reaction orders increased after deposition of the organophosphonic layers, and went from slightly negative to positive (Table 1), we assume that PAs could be sterically hindering this clustering process. 2-Butanol orders followed a similar but weaker trend, that could be attributed to the same phenomenon.

It is also important to consider how the coverages of other species, including the reaction product water, affect reactivity. Carrizosa and Munuera showed that water can adsorb onto the same centers that perform dehydration reactions ${ }^{10}$ and therefore can limit the reaction. Moreover, they also reported that the ability to displace water was the highest for ethanol, followed by 2-propanol and tertbutanol. The measured partial reaction orders for water showed a strong inhibition of $\mathrm{t}-\mathrm{BuOH}$ dehydration, a lower inhibition for 2-BuOH, and almost no effect on $1-\mathrm{BuOH}$. The fact that the desorption temperature for water on $\mathrm{TiO}_{2}$ anatase is $270^{\circ} \mathrm{C},{ }^{10}$ and that the olefin peaks in Figure 4 appear at roughly $340^{\circ} \mathrm{C}, 270^{\circ} \mathrm{C}$ and $180^{\circ} \mathrm{C}$ for $1-\mathrm{BuOH}, 2-$ $\mathrm{BuOH}$ and $\mathrm{t}-\mathrm{BuOH}$, respectively, supports the claim that water desorption should be more competitive for the more substituted alcohols. We note that slow displacement of water may be responsible for significant induction periods observed over the native catalyst during t-BuOH dehydration.

Interestingly, 4-FBPA suppressed the steady-state effect that water had on dehydration, as almost no dependence between the rates and water concentration was found (Table 2). These findings suggest that the presence of the monolayer allows for a faster displacement of water from the active site. Given the constant production of water in the system, faster water desorption would increase the observed rates, which can partly explain the promotion of dehydration activity by the presence of SAMs. Given the similar chemisorption behavior of water over all three 
modified surfaces (Figure S7), we theorize that the steady state behavior of water in presence of the alkyl SAMs should be similar to that of 4-FBPA, and therefore we consider the head group to be mainly responsible for this observed phenomenon.

\section{Effect of coatings on active site density}

Another key effect of PA modification is the potential to decrease the number of active sites through site-blocking effects. Previous work has shown that PA modification of $\mathrm{TiO}_{2}$ introduces some new Brønsted acid sites (as measured by infrared spectroscopy after pyridine adsorption), but sharply decreases the total number of (Lewis) acid sites as measured by ammonia $\mathrm{TPD}^{18,32}$. Perhaps the clearest indication of a decrease in the number of available active sites comes from the TPRS experiments. As shown in Figure 4, both unreacted alcohol desorption yield and (especially) the dehydration product yield were substantially decreased by the PA SAMs. Although the relationship between alkene yield and the nature of the tail group was not found to be consistent for all alcohols, 4FBPA modification was generally associated with higher yields than ODPA, especially for the dehydration of t$\mathrm{BuOH}$.

Self-assembled monolayer packing and surface density depends on the nature of the tail groups ${ }^{12}$. On $\mathrm{TiO}_{2}$, 4FBPA has been found to have a coverage of 3 molecule $/ \mathrm{nm}^{2},{ }^{17}$ while alkyl PAs have been reported to have higher coverages ${ }^{26}$. On $\mathrm{Al}_{2} \mathrm{O}_{3}$, MPA and ODPA had the highest coverages among many other PAs, with 5.6 and 4.9 molecule $/ \mathrm{nm}^{2}$, respectively ${ }^{33}$. The lower 4-FBPA coverage can be attributed to the spatial requirements ${ }^{34}$ of the benzyl rings in 4-FBPA. The ability of the tail group to govern the maximum coverages for the different tested species likely plays an important role in the overall outcome of the reactions.

The adsorption of 2-propanol on $\mathrm{TiO}_{2}$ (101) has been computationally studied, and two distinct non-dissociative binding modes were found to be plausible ${ }^{35}$. The less stable binding mode consists solely of an $\mathrm{H}-\mathrm{O}$ bond of the alcoholic $\mathrm{H}$ and the lattice bridge oxygen from the metal oxide, which has been related to a physisorption state due to the calculated small elongations of the bonds. The more stable configuration requires an $\mathrm{O}_{\text {alc }}-\mathrm{Ti}$ bond, while the $\mathrm{H}$ of the alcohol is attracted to one or two neighboring lattice oxygens. When a single oxygen attracts the $\mathrm{H}$, the difference in energies between the two described binding modes is $35 \mathrm{~kJ} / \mathrm{mol}^{35}$. The energies calculated from the Redhead model yield a $\sim 30 \mathrm{~kJ} / \mathrm{mol}$ difference between the unreacted alcohol and olefin peaks for 2-butanol (Table 3). Hence, the more loosely bound alcoholic species that desorbed at $\sim 140{ }^{\circ} \mathrm{C}$ and the more strongly adsorbed alcohols that desorbed as olefins at higher temperatures (Figure 4) could be linked to the two different binding modes reported in the literature.

Overall, we find that PAs can have a number of effects on the alcohol dehydration reaction mechanism. PA coatings stabilize the transition state for dehydration, with the more significant stabilization provided by 4FBPA attributed to its stronger dipole moment ${ }^{17}$. The PAs also appear to decrease the fractional coverage of strongly bound surface intermediates and water under reaction conditions, presumably via repulsive interactions with neighboring species. However, the site-blocking effects arising from PA deposition strongly reduce the number of active sites.

As a quantitative assessment of this idea, if kinetics obey an Arrhenius temperature dependence and a Langmuir site treatment is assumed, at the studied reaction temperature $\left(\sim 250^{\circ}{ }^{\circ} \mathrm{C}\right)$ and when adsorption and desorption steps do not limit the process (Equations S1-S2), a $\mathrm{TiO}_{2}$ anatase native surface could macroscopically behave similarly to a surface with $90 \%$ fewer sites and $10 \mathrm{~kJ} / \mathrm{mol}$ less in the dehydration activation energy, which is in the range of changes observed in these studies. However, relatively small shifts in reaction barriers, adsorption strengths, and reactions temperatures can influence whether coatings enhance or suppress reactivity (Supporting Information, Figure S6).

The net effect of PA modification this differs for different alcohols and coatings, but 4-FBPA generally appears to offer superior dehydration activity. This enhanced performance is attributed to the strong dipole moment and somewhat lower coverage of 4FBPA compared to the other coatings. Overall, the results suggest that design of PA-modified dehydration catalysts should perhaps focus on generating lower coverages that may better preserve the total number of active sites; this could potentially be done by depositing controlled sub-saturation levels of FBPA, for example.

\section{CONCLUSIONS}

The reactions of 1-butanol, 2-butanol and tert-butanol over native and phosphonic acid-functionalized $\mathrm{TiO}_{2}$ anatase have been studied using a combination of steady-state kinetic and temperature-programmed measurements. The rate of alcohol dehydrogenation was uniformly suppressed by the PAs, apparently due to site-blocking effects. On the other hand, the effect of the PAs on alcohol dehydration was found to depend in a synergistic fashion on both the PA structure and the degree of alcohol substitution. Stabilization of the dehydration transition state for the primary alcohol 1butanol was found to be the most significant, especially for the most electron-withdrawing PA SAM, 4-FBPA. The extent of promotion offered by PA functionalization was found to result from a balance between transition state stabilization and site blocking effects. Although site blocking by PAs was significant, it was also found that they likely suppress the adsorption of surface spectators or poisons.

\section{AUTHOR INFORMATION}




\section{Corresponding Author}

*Will.Medlin@colorado.edu

\section{Author Contributions}

J.B-S was in charge of 2-butanol and tert-butanol kinetic experiments, reaction barrier and order measurements and TPD experiments. L.D.E. was responsible for the 1-butanol kinetic experiments and characterization of the materials; J.B-S., J.W.M. wrote the manuscript and J.W.M. supervised the project.

\section{Funding Sources}

This work was supported by the Department of Energy, Office of Science, Basic Energy Sciences Program, Chemical Sciences, Geosciences, and Biosciences Division under Grant DESC0005239. J.B-S. was supported by a graduate Balsells Fellowship.

\section{Notes}

The authors declare no competing financial interest.

\section{ABBREVIATIONS}

SAMs, self-assembled monolayers; PAs, phosphonic acids; TPRS, Temperature Programmed Reaction Studies; TPD, Temperature Programmed Desorption; $\mathrm{TiO}_{2}$, anatase titania; MPA, methylphosphonic acid; ODPA, octadecylphosphonic acid; 4-FBPA, 4-fluorobenzylphosphonic acid.

\section{ASSOCIATED CONTENT}

\section{Supporting Information}

BET surface area table, IR spectra of the functionalized catalysts, ratio of dehydrogenation rates for functionalized to native $\mathrm{TiO}_{2}$, Arrhenius plots, time on stream reaction performance, dehydrogenation TPRS, water dosed TPD studies, number of siteactivity trade-off assessment. This information is available free of charge on the ACS Publications website.

\section{ACKNOWLEDGMENT}

The authors would like to thank Dr. Hans Funke for his laboratory assistance.

\section{REFERENCES}

(1) Huber, G. W.; Iborra, S.; Corma, A. Synthesis of Transportation Fuels from Biomass: Chemistry, Catalysts, and Engineering. Chem. Rev. 2006, 106 (9), 4044-4098. https://doi.org/10.1021/cr068360d.

(2) Dapsens, P. Y.; Mondelli, C.; Pérez-Ramírez, J. Biobased Chemicals from Conception toward Industrial Reality: Lessons Learned and to Be Learned. $A C S$ Catal. 2012, 2 (7), 1487-1499. https://doi.org/10.1021/cs300124m.

(3) Román-Leshkov, Y.; Barrett, C. J.; Liu, Z. Y.; Dumesic, J. A. Production of Dimethylfuran for Liquid Fuels from Biomass-Derived Carbohydrates. Nature 2007. https://doi.org/10.1038/nature05923.

(4) Robinson, A. M.; Hensley, J. E.; Will Medlin, J. Bifunctional Catalysts for Upgrading of BiomassDerived Oxygenates: A Review. ACS Catal. 2016, 6 (8), 5026-5043. https://doi.org/10.1021/acscatal.6b00923.

(5) C. Védrine, J. Heterogeneous Catalysis on Metal Oxides. Catal. MDPI 2017, 7 (341).

https://doi.org/10.3390/catal7110341.
(6)

Rekoske, J. E.; Barteau, M. A. Competition between Acetaldehyde and Crotonaldehyde during Adsorption and Reaction on Anatase and Rutile Titanium Dioxide. Langmuir 1999, 15 (6), 2061-2070. https://doi.org/10.1021/la9805140.

Rekoske, J. E.; Barteau, M. A. Kinetics and Selectivity of 2-Propanol Conversion on Oxidized Anatase TiO2. J. Catal. 1997, 165 (1), 57-72. https://doi.org/10.1006/jcat.1997.1467.

Roy, S.; Mpourmpakis, G.; Hong, D. Y.; Vlachos, D. G.; Bhan, A.; Gorte, R. J. Mechanistic Study of Alcohol Dehydration on $\gamma$-Al2O3. ACS Catal. 2012, 2 (9), 1846-1853. https://doi.org/10.1021/cs300176d.

Kang, M.; Dewilde, J. F.; Bhan, A. Kinetics and Mechanism of Alcohol Dehydration on $\gamma$-Al2O3: Effects of Carbon Chain Length and Substitution. ACS Catal. 2015, 5 (2), 602-612. https://doi.org/10.1021/cs501471r.

(10) Carrizosa, I.; Munuera, G. Study of the Interaction of Aliphatic Alcohols with TiO2: On the Mechanism of Alcohol Dehydration on Anatase. 1977, 200, 189-200.

Kostestkyy, P.; Yu, J.; Gorte, R. J.; Mpourmpakis, G. Structure-Activity Relationships on Metal-Oxides: Alcohol Dehydration. Catal. Sci. Technol. 2014, 4 (11) 3861-3869. https://doi.org/10.1039/C4CY00632A.

Schoenbaum, C. A.; Schwartz, D. K.; Medlin, J. W. Controlling Surface Crowding on a Pd Catalyst with Thiolate Self-Assembled Monolayers. J. Catal. 2013, 303, 92-99. https://doi.org/10.1016/j.jcat.2013.03.012.

Pang, S. H.; Schoenbaum, C. A.; Schwartz, D. K.; Medlin, J. W. Directing Reaction Pathways by Catalyst Active-Site Selection Using Self-Assembled Monolayers. Nat. Commun. 2013, 4, 1-6. https://doi.org/10.1038/ncomms3448.

Schoenbaum, C. A.; Schwartz, D. K.; Medlin, J. W Controlling the Surface Environment of Heterogeneous Catalysts Using Self-Assembled Monolayers. Acc. Chem. Res. 2014, 47 (4), 1438-1445. https://doi.org/10.1021/ar500029y.

Jia, X.; Ma, J.; Xia, F.; Xu, Y.; Gao, J.; Xu, J. Carboxylic Acid-Modified Metal Oxide Catalyst for Selectivity-Tunable Aerobic Ammoxidation. Nat. Commun. 2018, 9 (1), 1-7. https://doi.org/10.1038/s41467-018-03358-x.

Jia, X.; Ma, J.; Xia, F.; Gao, M.; Gao, J.; Xu, J. Switching Acidity on Manganese Oxide Catalyst with Acetylacetones for Selectivity-Tunable Amines Oxidation. Nat. Commun. 2019, 10 (1), 2338. https://doi.org/10.1038/s41467-019-10315-9.

Ellis, L. D.; Trottier, R. M.; Musgrave, C. B.; Schwartz, D. K.; Medlin, J. W. Controlling the Surface Reactivity of Titania via Electronic Tuning of SelfAssembled Monolayers. ACS Catal. 2017, 7 (12), 8351-8357. https://doi.org/10.1021/acscatal.7b02789.

Ellis, L. D.; Ballesteros-Soberanas, J.; Schwartz, D. K.; Medlin, J. W. Effects of Metal Oxide Surface Doping with Phosphonic Acid Monolayers on Alcohol Dehydration Activity and Selectivity. Appl. Catal. A 
Gen. 2019.

https://doi.org/10.1016/j.apcata.2018.12.009.

(19) De Klerk, A. Key Catalyst Types for the Efficient Refining of Fischer-Tropsch Syncrude: Alumina and Phosphoric Acid; 2011; Vol. 23. https://doi.org/10.1039/9781849732772-00001.

(20) Blanksby, S. J.; Ellison, G. B. Bond Dissociation Energies of Organic Molecules. Acc. Chem. Res. 2003, 36 (4), 255-263. https://doi.org/10.1021/ar020230d.

(21) McElwee, J.; Helmy, R.; Fadeev, A. Y. Thermal Stability of Organic Monolayers Chemically Grafted to Minerals. J. Colloid Interface Sci. 2005, 285 (2), 551556. https://doi.org/10.1016/j.jcis.2004.12.006.

(22) Busca, G.; Ramis, G.; Lorenzelli, V.; Janin, A.; Lavalley, J. C. FT-i.r. Study of Molecular Interactions of Olefins with Oxide Surfaces. Spectrochim. Acta Part A Mol. Spectrosc. 1987, 43 (4), 489-496. https://doi.org/10.1016/0584-8539(87)80049-1.

(23) Redhead, P. A. Thermal Desorption of Gases. Vacuum 1962, 12 (4), 203-211. https://doi.org/10.1016/0042207X(62)90978-8.

(24) Carrizosa, I.; Munuera, G.; Castanar, S. Study of the Interaction of Aliphatic Alcohols with $\mathrm{TiO} 2$ : Decomposition of Ethanol, 2-Propanol, and TertButanol on Anatase. J. Catal. 1977, 49, 265-277. https://doi.org/http://dx.doi.org/10.1016/00219517(77)90253-6.

(25) Tan, M.; Wang, G.; Zhang, L. Thermal Desorption in Nanocrystalline TiO2. J. Appl. Phys. 1996, 80 (2), 1186-1189. https://doi.org/10.1063/1.363727.

(26) Lu, H.; Wang, Y.; Wang, Y.; Liang, W.; Yao, J. Adjusting Phase Transition of Titania-Based Nanotubes via Hydrothermal and Post Treatment. RSC Adv. 2015, 5 (109), 89777-89782. https://doi.org/10.1039/c5ra17692a.

(27) Misono, M. Chemistry and Catalysis of Mixed Oxides 2013; Vol. 176. https://doi.org/10.1016/B978-0-44453833-8.00002-8.
Deshlahra, P.; Iglesia, E. Reactivity and Selectivity Descriptors for the Activation of C-H Bonds in Hydrocarbons and Oxygenates on Metal Oxides. $J$. Phys. Chem. C 2016, 120 (30), 16741-16760. https://doi.org/10.1021/acs.jpcc.6b04604.

(29) Knözinger, H.; Bühl, H.; Kochloefl, K. The Dehydration of Alcohols on Alumina XIV. J. Catal. 1972, 24, 57-68.

(30) Larsen, G.; Lotero, E.; Petkovic, L. M.; Shobe, D. S. Alcohol Dehydration Reactions over Tungstated Zirconia Catalysts. J. Catal. 1997, 169 (1), 67-75. https://doi.org/10.1006/jcat.1997.1698.

(31) Larsen, G.; Lotero, E.; Márquez, M.; Silva, H. Ethyl Tert-Butyl Ether (ETBE) Synthesis on H-Mordenite: Gas-Phase Kinetics and DRIFTS Studies. Journal of Catalysis. 1995, pp 645-655. https://doi.org/10.1006/jcat.1995.1330.

(32) Coan, P. D.; Griffin, M. B.; Ciesielski, P. N.; Medlin, J. W. Phosphonic Acid Modifiers for Enhancing Selective Hydrodeoxygenation over Pt Catalysts: The Role of the Catalyst Support. J. Catal. 2019, 372, 311-320. https://doi.org/10.1016/j.jcat.2019.03.011.

(33) Coan, P. D.; Ellis, L. D.; Griffin, M. B.; Schwartz, D. K.; Medlin, J. W. Enhancing Cooperativity in Bifunctional Acid-Pd Catalysts with Carboxylic AcidFunctionalized Organic Monolayers. J. Phys. Chem. C 2018, 122 (12), 6637-6647. https://doi.org/10.1021/acs.jpcc.7b12442.

(34) Khassanov, A.; Steinrück, H. G.; Schmaltz, T.; Magerl, A.; Halik, M. Structural Investigations of SelfAssembled Monolayers for Organic Electronics: Results from X-Ray Reflectivity. Acc. Chem. Res. 2015, 48 (7), 1901-1908. https://doi.org/10.1021/acs.accounts.5b00022.

Tian, F. H.; Wang, X.; Zhao, W.; Zhao, L.; Chu, T.; $\mathrm{Yu}, \mathrm{S}$. Adsorption of 2-Propanol on Anatase TiO2 (101) and (001) Surfaces: A Density Functional Theory Study. Surf. Sci. 2013, 616, 76-84. https://doi.org/10.1016/j.susc.2013.05.005. 